\title{
A Comparison of Youth's Value Systems: The Case of Vietnamese Ethnic Groups
}

\author{
Le To-Do-Quyen ${ }^{1}$, Norzarina Mohd-Zaharim ${ }^{1}$, Intan Hashimah Mohd Hashim ${ }^{1}$, Le Minh Thuan ${ }^{2} \&$ Rany Sam $^{3}$ \\ ${ }^{1}$ School of Social Sciences, Universiti Sains Malaysia, Malaysia \\ ${ }^{2}$ Ho Chi Minh City Medicine and Pharmacy University, Vietnam \\ ${ }^{3}$ School of Educational Studies, Universiti Sains Malaysia, Malaysia \\ Correspondence: Le To Do Quyen, School of Social Sciences, Universiti Sains Malaysia, 11800, Pulau Pinang, \\ Malaysia. Tel: 60-124-602-399. E-mail: gamen20032003@gmail.com
}

Received: April 13, 2014

doi:10.5539/ijps.v6n2p128
Accepted: May 4, 2014 Online Published: May 20, 2014

URL: http://dx.doi.org/10.5539/ijps.v6n2p128

\begin{abstract}
This paper aimed to examine and compare the value systems of youth from the ethnic minority and majority groups in the South of Vietnam. Rokeach' value theory and value system survey (Rokeach Value Survey - RVS) are employed to investigate these value systems. Research samples were conveniently selected from a total of 102 students $(60.6 \%$ females) in a youth ethnic minority vocational college and two public universities. The findings were consistent with the previous studies conducted in Vietnam and other developed countries. Results indicated that terminal values of students from both groups tended to have more emphasis on personal and political values that reflected the concern of psychological stability and independence. Youth from minority groups showed less tendency toward a relational and social orientation, whereas youth from ethnic majority group displayed a less concern on values related to hedonistic and individualistic values. For the instrumental values, both groups gave a higher ranking for moral values than competency and intrinsic values. Youth from ethnic minority groups tended to have more emphasize on accomplishment and competent values than youth from ethnic majority group. The terminal values of young people from ethnic minority and majority groups are more alike than their instrumental values. Significant differences between two groups were only found in some values. The findings contribute to the existenting literatures and suggest longitudinal studies on comparing value systems among ethnic groups in order to promote the value exchanged trend happened during the context of globalization in Vietnamese modern society.
\end{abstract}

Keywords: value system, terminal values, instrumental values, youth, ethnic majority, ethnic minority

\section{Introduction}

Values play a significant role in people's lives. While animal's actions are mainly based on natural instinct and their responses are preprogrammed, humans act based on free will. It means that to a large extent, people choose for themselves on how to act. Our choices are based on values which are beliefs about what is important in life (Hultman \& Gellerman, 2001). Rokeach (1973) considered values as determinant factors which can affect all kinds of human behaviour, especially social behaviour, including social actions, attitudes and ideology, moral judgments and justifications of self and others, comparisons of self with others, presentations of self to others, and attempts to influence others.

According to Golden (2002), values can be considered a complex set of standards which serves as a personal guide, policeman, judge and physician in human life. Our values do not only incite us to take a particular position in society, but also predispose us to prefer one particular philosophical, political or religious ideology than others. They determine the way we present ourselves in front of others and the framework we use in order to persuade and influence others. Our values are the basic assumptions, allowing us to rationalize beliefs, attitudes and actions that would otherwise be unacceptable personally or socially. Because of that, we can reserve our feelings of morality and competence which are one important essential element of self-esteem. Values serve as standards in human life and differentiate a human being from a non-human. In short, it is a distinctive human quality that is not shared with other species. 
Values have significant influences on the future of modern societies. Kinder (1994) stated that eight common values "can guide a troubled world through a tumultuous future" (p. 8): love, truthfulness, fairness, freedom, unity, tolerance, responsibility and respect for life. He conducted interviews with two dozen "men and women of conscience" from 16 nations around the world to explore the moral glue that will bring people to the twenty-first century. The results of that research suggested a pressing need for shared values in our age of global interdependence. Bok (1989), a theorist before Kinder, furthermore, had a deep awareness about the relationship between values and peace by linking values as a strategy for peace. From her view, the apparent question of whether the balance of power, or deterrence, or arms control agreements can offer an adequate protection against the danger of man's self-extermination. She also suggested that the answers for that question could be given by increasing concern for human values that would serve the cause of peace as well as by calling and describing practical measures that would reduce distrust and constitute a comprehensive strategy for peace.

\subsection{Values and Value Systems}

Values have played an important role in various disciplines such as sociology, psychology, anthropology and others; they have been considered a central concept in the social sciences. The centrality of the value concept was confirmed by Rokeach (1973): "The value concept... [is] able to unify the apparently diverse interests of all the sciences concerned with human behaviour" (p. 3). In the context of the social and personal organization and change, values also take a crucial role (Schwartz, 2009). Many other researchers in other fields also agree with them. They believe that societies and individuals are characterized by values and change throughout the time also can be traced by values. The motivational bases of attitudes and behaviours can be explained by values as well. Although the important role of values is obvious, until now there are still many different conceptions of this construct (Golden, 2002; Rokeach, 1973; Schwartz, 2007).

Rokeach (1973) defined value as "enduring belief that a specific mode of conduct or end-state of existence is personally or socially preferable to an opposite or converse mode of conduct or end- state of existence." (p. 5). Feather (1994), a psychologist, was influenced by the seminal contributions of Rokeach and used the term: "organized summaries of experience that capture the focal, abstracted qualities of past encounters, that have a normative or oughtness qualities about them, and that function as criteria or frameworks against which present experience can be tested. But they are not effectively neutral abstract structures. They are tied to our feelings and can function as general motives" (p. 130). Similarly, Golden (2002) developed value concepts based on the most parts of Rokeach theory. He agreed with the way value researcher Milton Rokeach defined and described "values" and "value system" in his book "The Nature of Human Values". Following that, Golden also gave his own definition: "A value is an enduring belief that a specific way of behaving or a specific life goal is personally or socially preferable to any other" (p. 5). Schwartz (2007), however defined value as "desirable, trans-situational goals, varying in importance, that serve as guiding principles in people's lives." (p. 261). Although there are various ways to define values they all seem to be agreeing with Rokeach, for the most parts about the values' features (Feather, 1994; Golden, 2002; Rokeach, 1973; Schwartz, 2007).

The idea that values are organized into systems has been one of the most important features of values. Therefore, value system is the "enduring organization of beliefs concerning preferable modes of conduct or end-state of existence along a continuum of relative importance" (Rokeach, 1973, p. 5). According to Rokeach, each value is ordered in priority with respect to other values in a value system. So that once a new value is possessed, it becomes integrated into an organized system of values. In other words, a reordering of priorities occurs once a change occurs because of the relation of values in value system. So, the total value system can be seen as remaining relatively stable over time because of this relative conception of values. But this relatively stable character of value system is also flexible enough to help the unique personality of the socialized process within a given culture and society that may be same and continued, at the same time, to allow the rearrangement of values priorities caused by changes in society, culture, and personal experiences. A value system, otherwise, can be viewed as a total number of values existing within a hierarchy (Golden, 2002). To emphasize both the benefits of hierarchical models and the importance of human values, Golden cited Maslow's well-known "Hierarchy of Needs" model. In his theory, Maslow defined self-actualization as the achievement of one's uniquely defined values. Schwartz (2007) explicated a structural aspect of values, namely, the dynamic relations among them and suggested that actions in pursuit of any value have psychological, practical, and social consequences that may conflict or may be compatible with the pursuit of other values.

\subsection{Two Kinds of Values}

Rokeach (1973), well-known as the first scientist who raised the theory about different kinds of values, believed that there are two kinds of values: instrumental values and terminal values. Although some scientists want to 
re-assess some parts of the Rokeach value theory, such as a value concept (Jemna \& Curelaru, 2009), structure of values (Braithwaite, 1982; Schwartz \& Bilsky, 1987) and value survey (Braithwaite \& Law, 1985; Parashar, Dhar, \& Dhar, 2004), but his two kinds of value theory has been almost accepted broadly.

According to Rokeach, terminal values are referred to desirable end-states of existence (such as world peace, wisdom, and happiness) while instrumental values refer to desirable modes of conduct (such as responsibility, cooperation, and customer service). It is really important to distinguish two kinds of values in order to address two major questions in human life: what do I want to achieve? How do I want to achieve it? (Golden, 2002). Rokeach (1973) suggested that the relation between instrumental and terminal values is that they were separately organized into a relatively enduring hierarchical organization along a continuum of importance. Golden (2002) agreed with the most parts of Rokeach's classification of values, but he prefers to call that two kinds of values as life values and operational values. In his point of view, life values are defined as values associated with your long term or ultimate aspirations which help you strive to achieve and maintain over your lifetime whilst operational values are those underlying beliefs that can be carried out in the activities of your day to day experience.

\subsection{Cross-Cultural Studies Based on Rokeach Value Survey and His Value Theories}

The definition and instrumentation of the value construct of Rokeach (1973) is more coherent and psychometrically sound than other theories and instruments available that time (Debats, 1996). His work has been largely influenced to the concepts about the nature of human values and caused a surge of empirical studies on the role of human values of psychologists and sociologists across cultures and ethnicities: Chinese (Tsang, 1993; Lau, 1988; Feather, 1986), Turkish (Cileli \& Tezer, 1998; Cileli, 2000), Papua New Guineans (Feather, 1986), Romany (Jemna \& Curelaru, 2009) and so on. Later value theorists created their own theories based the main points of Rokeach's theory and their developed value measuring instrument sharing most of its value with Rokeach Value Survey (SVS; Schwartz, 1992).

In many previous cross-culture studies, Rokeach Value Survey has been used widespreadly (Braithwate \& Law, 1985; because of some reasons as: It is simple in design and economical to administer to individuals and groups; its instructions are easily grasped by people between the ages of 11 and 90 , and that comparative data can be obtained for people within this age range; its responses are directly expressed in quantitative terms, thus eliminating the need to score it; and it elicits responses - ranking - that come from internal demands rather than from external stimulus characteristics (Rokeach, 1973). According to Feather (1986), when different cultures are compared, cross-cultural studies using Rokeach Value Survey can reveal a complex pattern of similarities and differences in value priorities. Many different possible orders of values can be organized that allows for considerable variation. Consequently, the distinctiveness of the individual, group, or nation should be taken into account overall pattern when making any comparisons involving single values.

\subsection{Ethnic Groups in the South of Vietnam}

In Southeast Asia, Vietnam is considered a country with the richest and most complex ethnicity with a population around 90 million comprising 54 ethnic groups that coexist peacefully. While one ethnic group makes up about $86 \%$ of the population Kinh or Viet, some other ethnic groups only have a mere hundred members (such as Brau and Odu). If the ethnic majority group Kinh lives mainly in the lowland and deltas, almost all of the other 53 ethnic groups are scattered over mountainous regions and the midland from the North to the South (Ho Chi Minh Communist Youth Union, 2006).

In the Central Highlands and the South of Vietnam, some tribes have lived there for thousands of years while others had migrated into the region over the past few centuries. Among those groups, their inhabitation areas are often limited by altitude; the latest arrivals, the higher elevations. Many of them are similar in village architecture, traditional rituals and have a rural - agricultural lifestyle with a long history of inter-tribal warfare. Because many of the tribes are semi-nomadic, they practise traditional farming by slash-and-burn methods which lead to the damage of the ever dwindling forests. The government has been trying to encourage and teach them to adopt more settled agriculture at lower altitudes to prevent the practices of destroying forests. The influences from outside has a slow effect on the rich, inherent culture of so many of Vietnam's ethnic minorities. While factors such as the introduction of electricity, modern medicine and education do create advantages, unfortunately such evolution has brought about the abandonment of many age-old traditions. But as can be seen, today, many tribes have been so assimilated into mainstream Vietnamese society: very few even dress in traditional garb and are found in the remote villages of the highlands, and only the women who do so, while the men prefer switch over to Vietnamese or western-style clothes. Thus, it is now more difficult to distinguish many of the tribes in the Central Highlands and the south from ordinary Vietnamese by dress alone. Members in each 
individual ethnic minority group share basic similar traits in their daily lives so that they can most easily be identified by differences in origin, language, dialect, physical features and hugely varied traditional dress. There are a number of similarities among the highland and southern groups that distinguish them from Viet people: most immediately obvious is the stilt house, the communal imbibing of rice wine, slash-and-burn farming practice and so on (Nguyen, 2012).

Because there was not much previous study on the value system of ethnic groups in Vietnam as well as in Highland Central and the South of Vietnam before. There is a national project focusing on values, values orientation and values education by Uan, Thac, and Trang (1995) used a value scale with 20 special general values and they found that the priority Vietnamese gave for those 20 values was as follows: peace, freedom, health, job, justice, knowledge, family, security, belief, career, goal of life, affection and gratitude, self-respect, truth, independence, love, creation, beauty, a prosperous life, and social status. Another study on the value system of young Vietnamese workers and students (Hac et al., 2007) with the scales of six values (happiness, health, knowledge, morality, wealth, and social status) and five values (health, knowledge, confident, intelligent and creative, and responsible). This paper aimed to examine and compare the value systems of youth from the ethnic, minority and majority groups in the South of Vietnam in order to find out the differences in their value systems that might help interpret the value exchange focused in Vietnamese modern society. The findings also can contribute to the limited literatures on value systems, differences of Vietnamese ethnic groups as well as give more chance to understand values differences among different cultures around the world. This study focused on a group of young people from both the ethnic majority and ethnic minority groups currently studying at a vocational college and two public universities. That group of young people represents the new generation in Vietnam, where the groups are no longer separated but they are sharing similar spaces and interact more with each other. Rokeach' value theory about two kinds of values and his value system survey (Rokeach Value Survey - RVS) are employed to explore these problems.

\section{Research Method}

\subsection{Participants}

Non-probability and convenience sampling method was used to select the participants. A total of 102 students, including 57 students from the ethnic majority group and 45 students from ethnic minority groups (minority ethnic groups such as Ede, Tay, Nung, Thai, Muong, Dao, Xe Dang, Gia Rai, San Chi, Van Kieu), who study in a youth ethnic minority vocational college and two public universities in Highland Central and the South of Vietnam, answered the questionnaire. The age of the respondents ranged from 17 to 24 (Mean $=21.54$, S.D $=$ $2.302)$ and more than half of them $(60.6 \%)$ were female.

\subsection{Measurement}

Value systems were assessed by using Rokeach's Value Survey (Rokeach, 1973). This instrument was translated from English into Vietnamese and was adapted for Vietnamese students. It consisted of two lists of values: instrumental and terminal values in alphabetical order. Each value was accompanied by a short description and a blank box. The task of respondents was to arrange each value in two separate value lists according to its importance to them as guiding principles in their lives. They were required to study each list of values carefully before ranking those two lists of values separately. First, they went through all values in the first list, then selected the value considered the most important to them and wrote the number 1 in the blank space next to that value. Then, they chose the second important value and wrote the number 2 in the blank space next to it. They continued to keep doing this until all 18 values have been ranked then they moved to the second list and ranked 18 values in the same way they did for the first list. The participants were encouraged to go back and change their order of any answers if they changed their mind. The measurement was based on the rank-ordering procedure instead of scoring each value chosen.

The researchers used the Rokeach Value Survey (RVS; Rokeach, 1973), which shares most of its value with the Schwartz's Value Survey (SVS; Schwartz, 1992) and included an additional set of value items (Vauclair, Hanke, Fischer, \& Fontaine, 2011). In this study, forward translation method was used for questionnaire translating. The translated questionnaire was sent to Vietnamese psychologists as well as to English experts for editing and correcting. For the Rokeach Value Survey (Vietnamese Version), we used the test - retest method to assess its reliability. The questionnaire was administered two times (one month apart). The data were assessed for the reliability ( 0.72 for total 36 value scale, 0.64 for terminal values sub-scale and 0.76 for instrumental values sub-scale). After achieving suitable reliability and validity, the questionnaire was used for data collection. 
The data were analysed by SPSS. The average value systems for the sample concerned was defined by the mean rankings for the terminal and instrumental values. In these value systems, lower means denote a higher relative value. Independent sample t-test was used to find out the differences when comparing the samples.

\subsection{Procedure}

Headmasters of universities and college confirmed their permissions. Respondents were informed of the purpose of this study and informed consent was obtained from them before they participated. 102 questionnaires were distributed to two public universities and one ethnic youth vocational college. Students participated in answering the questionnaire in lecture halls or meeting rooms and the data was then assessed.

\section{Results}

\subsection{Terminal Values of Youth from Ethnic Minority and Majority Groups in the South of Vietnam}

Table 1 presents terminal values of youth from an ethnic minority and majority groups in the South of Vietnam as well as the comparison between these groups. The four most important terminal values that youth from ethnic minority groups ranked were: family security, happiness, freedom, and equality, and the four least important terminal values were mature love, a sense of accomplishment, national security, and a world of beauty. In contrast, for youth from the ethnic majority group, the four most important terminal values were family security, equality, happiness and a comfortable life and the four least important terminal values were inner harmony, a sense of accomplishment, wisdom, and pleasure. It means students from both groups tended to more emphasis on personal and political values that reflect the concern for psychological stability and independence. While youth from minority groups showed less tendency toward a relational and social orientation, youth from ethnic majority group displayed a less concern on values related hedonistic and individualistic values.

To compare between two groups, there were not many differences in the way ethnic minority groups and the ethnic majority group ranked the 18 terminal values. They agreed on four highest values: family security, equality, freedom and happiness. This agreement also was found in some lower ranked values, such as: a sense of accomplishment, an exciting life, mature love, self-respect and social recognition. As for the rest of the terminal values, there were only slight differences that the two groups gave for each value.

Table 1. Mean, standard deviation and rank of terminal values

\begin{tabular}{lrrrrr}
\hline \multirow{2}{*}{ Terminal Values } & \multicolumn{2}{c}{ Ethnic majority group } & \multicolumn{2}{c}{ Ethnic minority groups } & \multirow{2}{*}{$t(p)$} \\
\cline { 2 - 5 } & \multicolumn{1}{c}{$M(S D)$} & \multicolumn{1}{c}{ Rank } & \multicolumn{1}{c}{$M(S D)$} & Rank & \\
\hline A comfortable life & $6.53(5.687)$ & 4 & $10.37(5.294)$ & 11 & $3.516\left(.001^{* * *}\right)$ \\
An exciting life & $8.96(5.103)$ & 7 & $9.18(4.281)$ & 6 & $0.237(.813)$ \\
A sense of accomplishment & $12.60(4.136)$ & 16 & $11.25(4.441)$ & 16 & $1.576(.118)$ \\
A world at peace & $8.42(5.663)$ & 6 & $10.11(6.576)$ & 9 & $1.363(.176)$ \\
A world of beauty & $10.73(5.361)$ & 13 & $14.04(4.516)$ & 18 & $3.375\left(.001^{* * *}\right)$ \\
Equality & $5.96(4.786)$ & 2 & $7.96(4.862)$ & 4 & $2.087(.390)$ \\
Family Security & $4.22(3.463)$ & 1 & $3.68(2.941)$ & 1 & $0.848(.398)$ \\
Freedom & $7.13(4.717)$ & 5 & $5.98(3.810)$ & 3 & $1.363(.176)$ \\
Happiness & $6.29(4.225)$ & 3 & $4.14(3.696)$ & 2 & $2.737(.007 *)$ \\
Inner harmony & $11.84(4.237)$ & 15 & $8.65(3.984)$ & 5 & $3.911\left(.000^{* * * * *)}\right)$ \\
Mature love & $11.09(3.636)$ & 14 & $11.09(5.121)$ & 15 & $0.001(.999)$ \\
National security & $10.67(4.447)$ & 12 & $12.49(4.964)$ & 17 & $1.931(.056)$ \\
Pleasure & $13.38(3.550)$ & 18 & $11.00(4.993)$ & 14 & $2.700\left(.008^{*}\right)$ \\
Salvation & $9.51(4.246)$ & 8 & $10.47(3.799)$ & 13 & $1.206(.231)$ \\
Self-respect & $10.56(4.775)$ & 11 & $10.28(4.329)$ & 10 & $0.304(.762)$ \\
Social recognition & $9.53(4.746)$ & 9 & $9.77(4.322)$ & 8 & $0.265(.791)$ \\
True friendship & $9.62(4.564)$ & 10 & $9.32(4.384)$ & 7 & $0.344(.731)$ \\
Wisdom & $13.33(3.879)$ & 17 & $10.46(4.637)$ & 12 & $3.340\left(.001^{* * *}\right)$ \\
\hline
\end{tabular}

Note. ${ }^{*} p<.05 ; * * p<.005 ;{ }^{* * *} p=.001 ; * * * * p<.001$. 
As shown in Table 1, significant differences between the two groups were only found in the ranking of six terminal values: a comfortable life $(t(91)=3.516 ; p=.001)$, a world of beauty $(t(85)=3.375 ; p=.001)$, happiness $(t(87)=2.737 ; p<.05)$, inner harmony $(t(91)=3.911 ; p<.001)$, pleasure $(t(99)=2.700 ; p<.05)$, wisdom $(t(99)=3.340 ; p=.001)$.

\subsection{Instrumental Values of Youth from Ethnic Minority and Majority Groups in the South of Vietnam}

Table 2 shows that youth from ethnic minority groups ranked the four most important instrumental values were honest, capable, helpful, and intellectual and the four least important instrumental values were courageous, ambitious, imaginative, and logical. In comparison, youth from the ethnic majority group gave the four most important rankings for following instrumental values: honest, courageous, responsible, and helpful and the four least important ranking for instrumental values: ambitious, broad-minded, imaginative, and logical. That means youth from ethnic minority groups tended to more emphasize on accomplishment and competent values than youth from ethnic majority group, but for both groups, they seem to be given higher ranking for moral values than competency and intrinsic values.

There were more differences revealed in the ranking of ethnic minority groups and the ethnic majority group for 18 instrumental values than 18 terminal values. These two groups had most agreements on "honest" as the most important value and "logical", "forgiving" and "imaginative" as the least important values. Two values received rather good agreement between ethnic minority and majority groups: "ambitious" and "helpful". In contrast, some other values got less agreement, such as: "responsible", "independent", "obedient", "polite" and "self-control".

Table 2. Mean, standard deviation and rank of instrumental values

\begin{tabular}{lrrrrr}
\hline \multirow{2}{*}{ Instrumental values } & \multicolumn{2}{c}{ Ethnic majority group } & \multicolumn{2}{c}{ Ethnic minority groups } & \multicolumn{1}{c}{$t(p)$} \\
\cline { 2 - 5 } & \multicolumn{1}{c}{$M(S D)$} & \multicolumn{1}{c}{ Rank } & \multicolumn{1}{c}{$M(S D)$} & \multicolumn{1}{c}{ Rank } & \\
\hline Ambitious & $10.58(5.774)$ & 15 & $11.44(6.196)$ & 16 & $0.718(.475)$ \\
Broad-minded & $11.22(4.532)$ & 16 & $9.23(5.507)$ & 8 & $1.960\left(.048^{*}\right)$ \\
Capable & $9.38(5.706)$ & 8 & $7.58(5.220)$ & 2 & $1.658(.100)$ \\
Cheerful & $9.16(4.472)$ & 7 & $10.02(4.738)$ & 13 & $0.935(.352)$ \\
Clean & $8.80(4.939)$ & 5 & $9.91(5.442)$ & 12 & $1.067(.288)$ \\
Courageous & $7.31(5.261)$ & 2 & $10.84(3.972)$ & 15 & $3.863\left(.000^{* * * *}\right)$ \\
Forgiving & $10.42(4.755)$ & 14 & $10.19(5.128)$ & 14 & $0.231(.817)$ \\
Helpful & $8.07(5.158)$ & 4 & $7.82(5.071)$ & 3 & $0.238(.813)$ \\
Honest & $7.16(5.580)$ & 1 & $6.61(4.742)$ & 1 & $0.530(.598)$ \\
Imaginative & $12.16(5.103)$ & 17 & $11.96(4.829)$ & 17 & $0.193(.847)$ \\
Independent & $9.40(5.246)$ & 9 & $9.60(5.151)$ & 11 & $0.190(.850)$ \\
Intellectual & $9.48(4.789)$ & 11 & $8.05(5.708)$ & 4 & $1.332(.186)$ \\
Logical & $12.58(4.812)$ & 18 & $13.47(3.606)$ & 18 & $1.075(.285)$ \\
Loving & $9.64(5.046)$ & 12 & $8.67(4.775)$ & 6 & $1.002(.319)$ \\
Obedient & $9.69(4.866)$ & 13 & $9.33(4.870)$ & 10 & $0.384(.702)$ \\
Polite & $9.11(4.863)$ & 6 & $9.32(4.634)$ & 9 & $0.217(.829)$ \\
Responsible & $7.93(4.287)$ & 3 & $8.09(4.227)$ & 5 & $0.182(.856)$ \\
Self-controlled & $9.47(4.703)$ & 10 & $8.68(4.548)$ & 7 & $0.850(.397)$ \\
\hline
\end{tabular}

Note. ${ }^{*} p<.05 ;{ }^{* *} p<.005 ; * * * p=.001 ; * * * * p<.001$.

Youth from ethnic minority and majority groups ranked the remaining seven instrumental values (broad-minded, capable, cheerful, clean, courageous, intellectual, and loving) very differently. But as can also see from Table 2, there were only two significant differences: broad-minded $(t(99)=1.960 ; p<.05)$, courageous $(t(79)=3.863 ; p$ $<.001)$. 


\section{Discussion and Conclusion}

The results of this study were consistent with the previous studies in Vietnam. Among these 20 values, Vietnamese has high agreement in ranking 11 highest values (peace, freedom, health, job, justice, knowledge, family, security, belief, career, and goal of life) and three lowest values in their value system (beauty, a prosperous life, and social status) (Uan et all., 1995). In comparison, youth from ethnic minority and majority groups in the South of Vietnam in the present study gave the highest priorities for some similar values as did the general Vietnamese in Uan et al.'s study, such as: peace, security, happiness, freedom, equality, and social recognition. Also in the study of Hac and his colleagues (2007), Vietnamese ranked six values in this order: health, morality, happiness, knowledge, wealth, and social status and ranked five values in the following order: knowledge, intelligent and creative, healthy, confident, and responsible.

When comparing the results from this study with previous studies around the world, we also found a complex pattern of similarities and differences in valued priorities. While adolescence is growing up, they want to have more personal freedom so family security is a value that usually decreases in its importance. But it is interesting that both youth from ethnic minority and majority groups in Vietnam ranked "family security" as the most important value and it reflects the most concern for family of Vietnamese youth. This is the shaping effects of a nation's history and culture on value priorities which can also be seen in the studies of Tsang (1993) and Cileli and Tezer (1998). Tsang (1993) found that some traditional values of the collective Chinese society such as family values were still apparent among the junior secondary school students as one of the most important values. And he said this phenomenon might be interpreted by the fact that although they want to have more personal freedom, but still be attached to their family for financial, emotional support and guidance. Similarly, Cileli and Tezer (1998) indicated that because of the conventional structure of Turkish society, which places great importance on family ties, Turkish students in their study ranked family security and inner harmony among the most important terminal values.

Rokeach (1973) reported that freedom was a stable value and it was ranked among the top values for all age groups in the American society and long-term changes of freedom's importance have been toward an increase rather than a decrease. This issue happened also in Vietnamese youth from ethnic groups, but youth from ethnic minority ranked freedom higher than youth from those of majority groups. Because ethnic minority groups live closer to the nature and not be closely involved in society as much as majority groups, so they experienced more freedom in their life and viewed it as one of important values. However, in the Turkish samples, freedom dropped from the four most important terminal values in 1989 to the four least important terminal values in 1992 and 1995 (Cileli, 2000).

The way youth of ethnic groups in Vietnam ranked honesty as the most important values in instrumental values are consistent with previous findings. Although it sometimes happens that honesty is ranked among the four least important instrumental values (Cileli, 2000) because the individualistic and competitive orientation were promoted by the market economy, but honestly - a value of self-direction - was reported to be the most stable of all 36 values, all age groups ranked it as the first value without exception (Rokeach, 1973, p. 81).

Beside the interesting similarities, of somewhat more interest are the differences that were obtained. In a study of Lau (1988) on Chinese university students in Hong Kong, he found that all of them tended to prefer terminal values that are more personal rather than social, and instrumental values that are competency rather than moral in nature. Similarly, Cileli (2000) demonstrated that the value orientations of the Turkish youth underwent major changes toward a more competitive and individualistic orientation. In contrast, junior secondary school students in Hong Kong showed a greater emphasis on peer relationship, family, achievement and inner peace (Tsang; 1993). While in this study, Vietnamese youth from ethnic majority and minority groups showed the opposite trend. Students from both groups tended to have more emphasis on personal and political values and give higher ranking for moral values than competency and intrinsic values. Specifically, while youth from minority groups showed less tendency toward a relational and social orientation, youth from ethnic majority group displayed a less concern on values related hedonistic and individualistic values. Additionally, youth from ethnic minority groups tended to emphasize more on accomplishment and competent values than youth from ethnic majority group. The most concern for moral values among instrumental values of Vietnamese youth reflects a consistency that might be related to Vietnam's culture and education system, which is often criticized for its emphasis on the very first thing should be learnt in school is proper manners in human relations, while knowledge and language are only secondary (Doan, 2005).

In comparison, Feather (1986) suggested that Chinese students assigned more importance to values related to competence and scholarship as well as to values concerning respect, hard work, and self-restraint, and to national 
security. Whereas, the Australian students saw self-related values and excitement as more important and assigned a higher priority to affiliative and altruistic values at the personal level. Another study by Feather also in 1986 indicated that Papua New Guineans showed a greater concern for equality, national security, salvation, social recognition, and with being ambitious, helpful, and obedient (along with some other differences depending upon which samples are compared). Cileli and Tezer, (1998) indicated that the value orientations of Turkish students revealed some of the cultural characteristics of society and they seemed to reflect important personality dispositions. There were various interesting differences of youth around the world in their value systems and most of these differences reflect the shaping effects of a nation's history and cultural characteristics on value priorities.

This study aimed to investigate value systems of youth from ethnic minority and majority groups in the South of Vietnam and compared between the two groups. The findings were consistent with the previous literature. Results revealed that for the terminal values, students from both groups tended to more emphasis on personal and political values that reflect the concern for psychological stability and independence. In addition, while youth from minority groups showed less tendency toward a relational and social orientation, youth from ethnic majority group assigned lower priority to related hedonistic and individualistic values. On the other hand, for the instrumental values, youth from ethnic minority groups tended to emphasize more on accomplishment and competence, values than youth from ethnic majority group, but for both groups, they seem to be given a higher ranking for moral values than competency and intrinsic values. There are more similarities in the terminal values of youth between ethnic minority and majority groups, compared to their their instrumental values. Significant differences between those two groups were only found in the orders youth ranked the two instrumental values (broad-minded and courageous) and six terminal values (a comfortable life, a world of beauty, happiness, inner harmony, pleasure, wisdom). The findings of this study contribute to the literature about human value systems around the world as well as in Vietnam. The differences and similarities between the ethnic majority and minority groups help understanding more about the value systems of different ethnic groups (one is the domain group and the others are minority groups in society) and it also suggests future long-term studies comparing value systems among ethnic groups in order to draw a values exchange picture of Vietnamese modern society in globalization context.

However, this is just a short-term study, which cannot fully exam the way values are maintained or transformed under present conditions, the way they operate to influence social institutions, and the way they are influenced by the changes in the society. Furthermore, this study cannot include participants from all ethnic minority groups in Vietnam and makes the comparison among them, but only those from some of particular ethnic minority groups in Highland Central and the South of Vietnam are included to compare with youths from the ethnic majority group. The comparison among ethnic minority groups is also a challenge for future studies. Thus, extensive future researches would be necessary in order to get a better understanding of the basic value orientations of Vietnamese society.

\section{Acknowledgements}

This research is supported by the fellowship to the first author from the Institute of Postgraduate Studies (IPS) at Universiti Sains Malaysia (USM), Malaysia. We are indebted to all students, headmasters and lecturers from Hong Bang International University, Ho Chi Minh City Medicine and Pharmacy University, and Centre Highland Youth Ethnic Minority Vocational College in Vietnam who participated in this research.

\section{References}

Bok, S. (1989). A strategy for peace: Human values and the threat of war. New York: Pantheon.

Braithwaite, V. A. (1982). The structure of social values: Validation of Rokeach's two-value model. British Journal of Social Psychology, 21, 203-211. http://dx.doi.org/10.1111/j.2044-8309.1982.tb00541.x

Braithwaite, V. A., \& Law, H. G. (1985). The structure of human values: Testing the adequacy of the Rokeach Value Survey. Journal of Personality and Social Psychology, 49, 250-263. http://dx.doi.org/10.1037/0022-3514.49.1.250

Cileli, M. (2000). Change in value orientations of Turkish youth from 1989 to 1995. The Journal of Psychology, 134(3), 297-305. http://dx.doi.org/10.1080/00223980009600869

Cileli, M., \& Tezer, E. (1998). Life and value orientations of Turkish university students. Adolescence, 33(129), 219-228.

Debats, D. L. (1996). The structure of human values: A principal components analysis of the Rokeach value survey (RVS) (Unpublished doctoral dissertation). University of Groningen, Groningen, Netherlands. 
Doan, D. H. (2005). Moral education or political education in the Vietnamese educational system? Journal of Moral Education, 34(4), 451-463. http://dx.doi.org/10.1080/03057240500414733

Feather, N. T. (1986). Cross-cultural studies with the Rokeach Value Survey: The Flinders program of research on values. Australian Journal of Psychology, 38(3), 269-283. http://dx.doi.org/10.1080/00049538608259014

Feather, N. T. (1986). Value systems across cultures: Australia and China. International Journal of Psychology, 21, 697-715. http://dx.doi.org/10.1080/00207598608247616

Feather, N. T. (1994). Human values and their relation to justice. Journal of Social Lisues, 50, 129-151. http://dx.doi.org/10.1111/j.1540-4560.1994.tb01201.x

Golden, J. P. (2002). Values arrangement list: Understand your values. Mount Laurel, NJ: ORA, Inc.

Hac, P. M., Chi, V. T. M., Huy, N. V., Huong, L. T., Huong, P. M., Huong, D. T. M., ... Phuc, L. D. (2007). Nghiên cứu giá trị nhân cách theo phương pháp NEO PI-R cải biên [Studying character values based on adapted methodology NEO PI-R]. Ha Noi: Khoa hoc xa hoi.

Ho-Chi-Minh-Communist-Youth-Union. (2006). Ethnic groups. Retrieved from http://english.doanthanhnien.vn/Article-category/335/Ethnic.htm

Hultman, K., \& Gellerman, B. (2001). Balancing individual and organizational values: Walking the tightrope to success. US: Jossey-Bass Inc.

Jemna, D. V., \& Curelaru, M. (2009). Reception of values among students. Analele Stiintifice ale Universitatii "Alexandru Ioan Cuza" din Iasi - Stiinte Economice, 56, 550-562.

Kinder, R. M. (1994). Universal human, finding an ethical common. The Futurist, 28, 8-13.

Lau, S. (1988). The value orientations of Chinese University students in Hong Kong. International Journal of Psychology, 23, 583-596. http://dx.doi.org/10.1080/00207598808247787

Nguyen, L. (2012). 54 ethnic people of Viet Nam. Retireved from http://vietnamheritagetravel.com/news/1384-54-ethnic-people-of-vietnam.html

Parashar, S., Dhar, S., \& Dhar, U. (2004). Perception of values: A study of future professionals. Journal of Human Values, 10, 143-152. http://dx.doi.org/10.1177/097168580401000207

Rokeach, M. (1973). The nature of human values. New York: Free Press.

Schwartz, S. H. (1992). Universals in the content and structure of values: Theory and empirical tests in 20 countries. In M. Zanna (Ed.), Advances in experimental social psychology (Vol. 25, pp. 1-65). New York: Academic Press.

Schwartz, S. H. (2007). Basic human values: Theory, methods, and applications. Risorsa Uomo: Rivista di Psicologia del Lavoro e dell' Organizzazione, 13, 261-283.

Schwartz, S. H. (2009). Basic human values. Paper presented at the Cross-national comparison seminar on the quality and comparability of measures for constructs in comparative research: Methods and applications, Bolzano (Bozen), Italy.

Schwartz, S. H., \& Bilsky, W. (1987). Toward a universal psychological structure of human values. Journal of personality and Social Psychology, 53, 550-562. http://dx.doi.org/10.1037/0022-3514.53.3.550

Tsang, W. M. (1993). A study on value orientations of junior secondary school students in Hong Kong. Master of Education, The University of Hong Kong, Hong Kong.

Uan, N. Q., Thac, N., \& Trang, M. V. (1995). Giá trị - Định huoóng giá trị nhân cách và giáo dục giá trị [Values - Orienting character values and educating values]. Ha Noi: Giao Duc.

Vauclair, C.-M., Hanke, K., Fischer, R., \& Fontaine, J. (2011). The structure of human values at the culture level: A meta-analytical replication of Schwartz's value orientations using the Rokeach Value Survey. Journal of Cross-Cultural Psychology, 42(2), 186-205. http://dx.doi.org/10.1177/0022022110396864 


\section{Copyrights}

Copyright for this article is retained by the author(s), with first publication rights granted to the journal.

This is an open-access article distributed under the terms and conditions of the Creative Commons Attribution license (http://creativecommons.org/licenses/by/3.0/). 